\title{
A IDENTIFICAÇÃO DESVELADA NA ANÁLISE DO DISCURSO DE PROFESSORES DE INGLÊS EM FORMAÇÃO INICIAL
}

\author{
Luciane Kirchhof Ticks (UFSM/CAPES) \\ Luticks@terra.com.br
}

\begin{abstract}
RESUMO
Este artigo procura discutir o perfil identitário do aluno de Letras em formação inicial, tomando como embasamento teórico a concepção de Identificação em Fairclough (2003), que engloba uma identidade social e uma individual. Segundo o autor, a primeira está relacionada às circunstâncias sociais nas quais o indivíduo nasce. $A$ segunda é adquirida mais tarde, quando o indivíduo assume papéis sociais. Para a realização deste artigo, foram elaborados e aplicados dois questionários e entrevistas com seus alunos cursando o primeiro semestre do curso de Letras/Inglês da UFSM. Na análise dos questionários e entrevistas, utilizei a proposta de análise de Fairclough, focalizando duas características textuais: a modalidade e a avaliação. Os resultados da análise indicam que grande parte desses alunos, futuros profissionais não se percebem, não se reconhecem "Professores de Inglês". Seu interesse pelo curso de Letras está relacionado à possibilidade de acesso à aprendizagem de línguas e às oportunidades que o conhecimento destas pode trazer, como, por exemplo, viajar.
\end{abstract}

\section{INTRODUÇÃO}

O professor não tem identidade. A afirmação é tão recorrente que, há muito, deixou a academia e virou senso comum, podendo ser ouvida em diferentes contextos: nas conversas entre alunos, professores e pais, nos meios de comunicação, nas instituições de ensino, nos órgãos públicos educacionais; enfim, nos mais diversos universos sociais. O comentário parece carregar o pressuposto de que tal perfil identitário, hoje ausente no professor, lhe garantiria coerência e homogeneidade, consistência e um sentido de completude profissional. Tal concepção, reflexo da filosofia cartesiana, entende o ser como indivíduo único e autoconsciente do seu papel em sociedade, pensamento iluminista que perdura até hoje (Rajagopalan, 2002:344-46). Identidades, todavia, são construídas e constituídas sóciohistoricamente e, portanto, carregam o traço característico da heterogeneidade, da inconstância e da eterna reconstrução. A identidade deveria ser entendida, portanto, enquanto:

...construção, como um processo nunca completado - como algo sempre "em processo" (grifo do autor). Ela não é, nunca, completamente determinada - no sentido de que se pode sempre, "ganhá-la" ou "perdê-la" (grifos do autor); no sentido de que ela pode ser, sempre, sustentada ou abandonada. (Hall, 2005: 106).

Esse processo, segundo Rajagopalan (1998:41 apud 2002: 344), "se constrói na língua e através dela". Nesse sentido, não podemos entender o indivíduo como portador de uma identidade fixa que se encontra anteriormente ou fora da língua (Idem).

$\mathrm{Na}$ tentativa de problematizar o processo de construção identitária do professor - e, em particular, do professor de línguas, diferentes pesquisas têm sido desenvolvidas e procuram jogar luz sobre esta que é uma discussão difícil e complexa. Para citar alguns exemplos, Gri- 
goleto (2005) focaliza a dimensão simbólica da ideologia e enfatiza seu papel nos processos identitários. Rajagopalan (2002) discute a constituição identitária na escritura do gênero memorial utilizado no processo de seleção em concursos públicos. Vereza (2002), por sua vez, explora a natureza da indeterminação identitária ao traçar um paralelo entre o falante nativo e o estudante brasileiro de Letras.

O Grupo de Formação de Professores da PUC/SP, coordenado pelas professoras Celani, Liberali e Magalhães, tem dado particular atenção ao estudo de novas constituições da cultura na escola e das identidades profissionais. Em artigo, Celani \& Magalhães (2002) discutem uma proposta de reconstituição identitária entre professores de inglês através do questionamento de suas representações sobre o que seja identidade profissional. Celani (2001) também questiona a restrita formação do professor de Letras, que estabelece um perfil profissional que está longe de garantir o status de uma profissão. Por sua vez, Gimenez (2004) argumenta que, por ser tratado boa parte do curso enquanto aluno, o futuro professor de línguas tem dificuldade para construir o seu perfil identitário enquanto professor.

A pesquisa narrativa também perpassa à construção identitária. Paiva (2005), por exemplo, trata das memórias de aprendizagem de professores de língua inglesa e Telles $(2002,1999)$ ressalta como a pesquisa narrativa pode contribuir para que os professores se tornem agenciadores de reflexão e autores de suas próprias representações. Paralelamente, Abraão (2004) analisa narrativas de histórias de vida para discutir crenças, pressupostos, conhecimentos que permeiam o discurso de alunos de Letras/Inglês em formação inicial.

Nesse sentido, este artigo procura contribuir para a discussão do processo identitário do professor de línguas, em particular, de língua inglesa, por meio da identificação de como esse perfil identitário se constitui no discurso de alunos de Letras/Inglês em formação inicial.

\section{PRESSUPOSTOS TEÓRICOS}

A construção da identidade do aluno pré-serviço, assim como de todo e qualquer indivíduo, começa na tenra infância, nas relações que estabelece com os outros no contexto social no qual é criado. Nesse sentido, o espaço social no qual ele se desenvolve deve ser compreendido enquanto processo dialético em curso, composto de três momentos: a exteriorização, a objetivação e a interiorização (Berger \& Luckmann, 1985: 173). O indivíduo exterioriza seu próprio ser no mundo social e interioriza este mundo como uma realidade objetiva.

A apropriação subjetiva da identidade e a apropriação subjetiva do mundo social são apenas aspectos diferentes do mesmo (grifo do autor) processo de interiorização, mediatizado pelos mesmos (grifo do autor) outros significados (Idem: 178).

Vale ressaltar que a criança identifica-se com o outro por uma multiplicidade de modos emocionais e interioriza o mundo como sendo o único possível, aquele que ela experienciou no convívio com seus pais. É por isso que o mundo interiorizado na socialização primária se torna muito mais sedimentado na consciência do que os mundos interiorizados nas socializações secundárias (Idem: 180). Estas compreendem qualquer processo subseqüente que introduz um indivíduo já socializado em novos setores do mundo objetivo de sua sociedade. 
A socialização secundária é a interiorização de "submundos" institucionais ou baseados em instituições. A extensão e caráter destes são, portanto, determinados pela complexidade da divisão do trabalho e a concomitante distribuição social do conhecimento (Ibidem: 184-85).

Se traçarmos um paralelo com o conceito de identidade social e individual proposto por Fairclough (2003: 223), podemos reconhecer essas duas dimensões descritas por Berger \& Luckmann. Para Fairclough, parte do que chama identidade social está intrinsecamente relacionada às circunstâncias sociais nas quais o indivíduo nasce e sofre a primeira socialização. A outra parte é adquirida mais tarde, quando o indivíduo assume papéis sociais, como, por exemplo, a profissão que exerce. Fairclough igualmente reconhece a relação dialética existente entre esses dois aspectos da identidade.

Por sua vez, Hall utiliza o termo "identidade" para significar o ponto de partida, ou de sutura, como chama, entre os discursos e as práticas que tentam nos "interpelar", nos falar ou nos convocar de modo que tomemos o lugar de sujeitos sociais de discursos particulares (2005: 111-12). Assim, entende que as identidades são pontos de apego temporário às posiçõesde-sujeito construídas pelas práticas discursivas (Hall, 1981: 106 apud Hall, 2005:112).

De outro modo, Fairclough (Idem: 160-61) destaca, ainda, que para desenvolvermos a identidade social no seu sentido mais completo, precisamos ser capazes de assumir papéis sociais e personificá-los, ou seja, caracterizando esses papéis com traços da nossa própria personalidade (individual). Assim, relata que o desenvolvimento completo enquanto agente social está dialeticamente interconectado com o desenvolvimento da personalidade.

Nesse sentido, Fairclough entende que ao pesquisamos sobre Identificação - como as pessoas se identificam e são identificadas por outros, através da análise textual, estaremos focalizando essa dialética entre identidade pessoal e social: o modo de ser do indivíduo social, ou ainda, sua identidade no aspecto discursivo da linguagem, que Fairclough chama de "estilos".

Paralelamente à Identificação, a proposta de análise textual de Fairclough (Idem: 28) é composta por outras duas dimensões: a Representação e a Ação. A primeira estaria relacionada ao conhecimento adquirido pelo indivíduo e ao controle que ele tem sobre o mundo. Nesse sentido, "representariam" os significados construídos sócio-historicamente pelo indivíduo à medida que ele interage em sociedade dentro das formações sociais a que pertence (Castro, 2004: 39). A Ação, por sua vez, destacaria as relações (de poder) com os outros dentro de uma prática social.

Embora reconheça que Representação, Ação e Identificação estejam relacionadas dialeticamente, são igualmente processos distintos. Neste artigo, concentro-me na última, procurando destacar as marcas textuais da Identificação nos textos dos alunos de Letras/Inglês, na medida em que falam sobre si mesmos: o sujeito evocado pela atividade da palavra (Foucault, 2004: 68).

\section{2 - Metodologia}

Para a realização desta pesquisa, foram aplicados dois questionários com alunos do primeiro semestre do curso de Letras/Inglês, que já fazem parte da nova base curricular da UFSM. O 
primeiro questionário, que chamei de sócio-econômico, procurou destacar o nível sócioeconômico dos alunos e a escolaridade familiar. O segundo questionário, intitulado psicossocial, procurou investigar o background sócio-cultural dos alunos (interesses pessoais, no período em que estavam na escola, em termos de disciplinas favoritas, leituras, atividades extracurriculares, e suas aspirações profissionais e expectativas em relação ao curso que agora iniciam). No total, foram respondidos 30 questionários psicossociais e 29 sócioeconômicos. Os participantes, nos questionários, serão identificados alfa-numericamente, da seguinte forma:

\section{P20 - Participante número 20}

$\mathrm{Na}$ análise dos questionários, utilizei procedimentos de cunho quantitativo e qualitativo. Reuni o recurso quantitativo, paralelamente ao qualitativo, principalmente para identificar os percentuais indicativos de preferência por disciplinas e assuntos favoritos, atividades extracurriculares (no período em que os participantes estavam na escola) ou, ainda, a escolha de Letras/Inglês como primeira opção no Vestibular/Peies, por exemplo. O questionário sócioeconômico possibilitou a identificação e análise, inter-relacionadamente, das seguintes informações: origem, escolaridade, renda, tipo de moradia, bem como hábitos de leitura e acesso ao computador/internet.

Para identificar o nível de escolarização familiar, especificamente, optei por calcular a média de anos de estudo família/participante ${ }_{2}$ porque as famílias variavam muito em número. Algumas apresentavam dois membros e outras 6 . O número absoluto não seria significativo. Assim, estabeleci o seguinte critério: Ensino Fundamental Incompleto (4 anos de estudo), Ensino Fundamental Completo (8 anos), Ensino Médio Incompleto (9,5 anos), Ensino Médio Completo (11 anos), Ensino Superior Incompleto, nível de Graduação,(13,5 anos), Ensino Superior Completo, nível de Graduação, (16 anos), Ensino Superior Incompleto, nível de pósGraduação (17 anos) e Ensino Superior Completo, nível de Pós-Graduação, (18 anos).

Para a análise da Identificação/Estilos, dentro da perspectiva proposta por Fairclough (2003: 159), procurei focalizar duas características textuais: a modalidade e a avaliação. Ambas contribuem para tentarmos perceber em que medida os participantes se comprometem com o que dizem, ou seja, com seus textos. Segundo Fairclough (Idem), o modo como as pessoas se comprometem tem grande relevância na construção de suas identidades e como estas se manifestam no texto (Idem: 164).

A modalidade significa o julgamento feito pelo falante das probabilidades ou obrigações envolvidas no seu discurso (Halliday, 1994: 89). As modalidades podem ser associadas a diferentes tipos de trocas e funções de fala. A modalidade epistêmica é utilizada para a troca de conhecimento, que se realiza por meio de declarações (o autor se compromete com a verdade) ou perguntas (o autor leva o outro ao comprometimento com a verdade). As declarações e as perguntas podem ser afirmativas e negativas, com ou sem modalização. Exemplo: The window is open/The window might be open. (Fairclough, 2003: 169).

Já a modalidade deôntica é utilizada na troca de atividade. Pode estar relacionada à função da linguagem que expressa obrigação ou necessidade (uma ordem), por meio de prescrições (open the window!), prescrições modalizadas (you should open the window) ou impedimentos (Don't open the window). Nesse caso, há um comprometimento do autor com essa obrigação. Por outro lado, a função pode ser de oferta ou proposta, que pressupõe o comprometi- 
mento do autor com a oferta realizada. Assim, podemos ter uma promessa ( $/$ will open the window), uma recusa (I won't open the window), ou, ainda, promessa e recusa modalizadas (I May open the window/I might not open the window) (Idem).

$\mathrm{Na}$ análise do questionário psicossocial, foram consideradas as categorias de modalidade ${ }^{1}$ em destaque na Tabela 3.1.

Tabela 3.1 - Categorias de Modalidade

\begin{tabular}{|c|c|}
\hline Categorias & Exemplos \\
\hline Verbos modais & $\begin{array}{l}\text { Poder, ter permissão para, dever. } \\
\text { Ex. A gente não tinha permissão para.. }\end{array}$ \\
\hline Advérbios modais & $\begin{array}{l}\text { Certamente, possivelmente. } \\
\text { Ex. Eu possivelmente farei outra faculdade }\end{array}$ \\
\hline $\begin{array}{l}\text { Comentários que destacam processos men- } \\
\text { tais }\end{array}$ & $\begin{array}{l}\text { Cativar, atrair, achar, pensar. } \\
\text { Ex. O inglês me cativa. }\end{array}$ \\
\hline Particípio com função de adjetivos & $\begin{array}{l}\text { Requerido, exigido, obrigado. } \\
\text { Ex. A disciplina era exigida na escola... }\end{array}$ \\
\hline Adjetivos modais & $\begin{array}{l}\text { Possível, provável, certo. } \\
\text { Ex. É certo que eu quero estudar inglês. }\end{array}$ \\
\hline Advérbios de freqüência & $\begin{array}{l}\text { Freqüentemente, sempre, nunca. } \\
\text { Ex. Eu sempre gostei de inglês. }\end{array}$ \\
\hline $\begin{array}{c}\text { Hedges } \\
\text { Expressões mitigadoras que denotam a im- } \\
\text { precisão do discurso }\end{array}$ & $\begin{array}{l}\text { Meio, um tanto. Eu não sei se.., Como você sabe... } \\
\text { Ex. Eu sou meio quieto. }\end{array}$ \\
\hline $\begin{array}{l}\text { Discurso indireto - atribuição de um comentá- } \\
\text { rio a outra pessoa }\end{array}$ & $\begin{array}{l}\text { Ex. Me disseram que na universidade tudo seria dife- } \\
\text { rente. }\end{array}$ \\
\hline
\end{tabular}

Essas marcas modalizadoras podem ser relacionadas a outros elementos textuais que contribuem para a construção da Identificação dos participantes. Por exemplo, as marcas de pessoa (Eu/nós) no texto (Eu acho que a universidade não prepara os alunos... em oposição a A Universidade não prepara....) destacam igualmente o comprometimento (ou a falta de) do autor com sua afirmação.

No que se refere à avaliação, levei em consideração as afirmações que expressam desejos, vontades, ou seja, o que se quer em contrapartida ao que não se quer; o que é bom em oposição ao que é mau. Exemplo: Um livro bom - um livro ruim. As afirmações avaliativas, destaca Fairclough (2003: 173), são mais obviamente realizadas por processos relacionais. Estes, por sua vez, representam as categorias de atribuição e identificação. Pertencem aos processos de "ser" e podem ser realizados através do verbo "ser" ou de similares - "parecer", "tornar-se", "ficar", "andar", bem como os verbos "ter, "possuir" e pertencer (Cabral, 2002: 22). As categorias de avaliação utilizadas na análise dos comentários retirados do questionário psicossocial estão em destaque na Tabela 3.2.

Tabela 3.2 Categorias de Avaliação

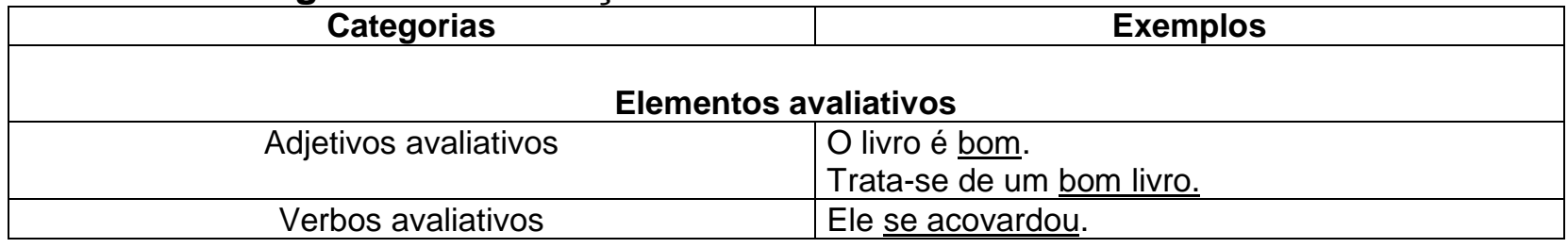

\footnotetext{
${ }^{1}$ As categorias de modalidade e avaliação utilizadas nesta análise foram sugeridas por Fairclough (2003: 170-173).
} 


\begin{tabular}{|c|c|}
\hline Advérbios avaliativos & Ele ensina corretamente. \\
\hline Exclamações & Que aula sensacional! \\
\hline $\begin{array}{l}\text { Avaliações que qualificam a importân- } \\
\text { cia/necessidade. }\end{array}$ & Está é uma matéria relevante. \\
\hline \multicolumn{2}{|c|}{ Afirmações com modalidade deôntica ou Processos afetivos mentais avaliativos } \\
\hline $\begin{array}{c}\text { Marcas explícitas da avaliação do autor através do } \\
\text { uso de modalização. }\end{array}$ & $\begin{array}{l}\text { Eu acho o professor deve mostrar o valor do seu } \\
\text { trabalho por meio do que faz. }\end{array}$ \\
\hline $\begin{array}{l}\text { Avaliações afetivas com a utilização de processos } \\
\text { relacionais. O atributivo é afetivo. }\end{array}$ & Este método é fascinante. \\
\hline \multicolumn{2}{|c|}{ Valores assumidos } \\
\hline Indicados por verbos como ajudar. & $\begin{array}{l}\text { As universidades ajudam as pessoas na constru- } \\
\text { ção do seu conhecimento. }\end{array}$ \\
\hline
\end{tabular}

Parece válido lembrar que uma avaliação pode apresentar diferenças em termos de intensidade. Por exemplo, os verbos relacionados a processos mentais, como gostar, adorar e odiar deixam transparecer a intensidade do comprometimento do falante com sua afirmação. De mesma forma, o uso de adjetivos, como bom, ótimo ou fantástico, e advérbios representados nos seguintes exemplos: Ele ensina bem e Ele ensina maravilhosamente.

Paralelamente aos questionários, fiz 6 (seis) entrevistas semi-estruturadas, com alunos que responderam aos questionários, no sentido de que narrassem um pouco da sua história de escolha do curso de Letras/Inglês. Esses alunos não foram escolhidos por mim. Eles se candidataram, voluntariamente, para participar das entrevistas, logo após a aplicação dos questionários. As entrevistas foram realizadas com base na seguinte pergunta:

O que te levou a estudar Letras/Inglês? Podes contar um pouco da tua história, sobre o momento em que decidiste fazer o curso?

$\mathrm{Na}$ análise das narrativas, procurei identificar em que medida os depoimentos dados pelos alunos constróem um perfil identitário (Identificação) semelhante ou diferente daquele discutido na análise do questionário psicossocial. Nesse sentido, tentei estabelecer relações de significado entre os resultados obtidos no questionário e as histórias contadas pelos alunos nas entrevistas. Segundo Telles (2002: 107), o objetivo da análise de narrativas é o de captar os significados que os eventos narrados têm para o participante. As narrativas foram identificadas do seguinte modo:

$$
\text { N1 - Narrador número } 1 .
$$

\section{ANÁLISE DOS RESULTADOS}

\subsection{0 questionário socioeconômico}

A análise do questionário sócio-econômico revelou que a grande maioria, ou seja, 25 participantes $(86,21 \%)$, têm origem urbana (Anexo A). Além disso, pude verificar que a média de pessoas por família é de 4,2 pessoas e, grande parte $(82,8 \%)$ das famílias dos participantes mora em casa própria, com renda familiar média de $R \$ 2.637,50$ (cerca de 8,7 salários mínimos). Esses valores salariais podem, entretanto, não ser considerados de grande representação, já que 44,83\% dos participantes informaram desconhecer a renda familiar. 
Em relação à escolaridade, quase a metade dos participantes, 13 (44,83\%), estudou em escola particular e pública e um número também significativo, 9 (31,03\%), apenas em escola pública (Anexo A). Isso significa dizer que mais da metade dos participantes passou boa parte dos seus anos escolares em instituições públicas. A média de anos de estudo per capita por família indica que 55,16\% (16 participantes) chega a ter 16 anos de estudo, o que compreenderia o ensino médio e superior, e 11 deles (37,93\%) podem alcançar até 11 anos (Anexo A).

Em relação à leitura de jornais e revistas, pude perceber que 20 participantes $(68,97 \%)$ afirmam ler jornais e 18 deles $(62,07 \%)$, revistas, diariamente. Entre as revistas, os gêneros mais procurados são as semanais de assuntos diversos (41,38\% dos participantes), como "Isto E" e "Veja". Outros 10,34\% responderam que, além dessas revistas, se interessam também por aquelas de popularização da ciência, como a "Super Interessante".

Ao cruzar essas informações, constatei, ainda, que quanto maior a escolaridade, maior a freqüência de leitura de jornais e o acesso a Internet (Tabela 4.1). Vale ressaltar que, entre aqueles que acessam diariamente ou freqüentemente (três vezes por semana) à Internet, o fazem para a realização de pesquisa $(58,62 \%)$ e, em um segundo momento, para a checagem de e-mails $(55,18 \%)$.

\section{Tabela 4.1 - Média Educacional x Uso do Computador x Internet x Leitura de Jornais}

(\%)

\begin{tabular}{|c|c|c|c|c|c|c|c|c|}
\cline { 3 - 8 } & Participantes & \multicolumn{2}{|c|}{$\begin{array}{c}\text { Usa Compu- } \\
\text { tador }\end{array}$} & \multicolumn{2}{c|}{ Usa Internet } & \multicolumn{2}{c|}{ Lê Jornais } & \multicolumn{1}{c|}{} \\
\hline & & Sim & Não & Sim & Não & $\begin{array}{c}\text { Todo } \\
\text { dia }\end{array}$ & $\begin{array}{c}\mathbf{1} \text { X pem } \\
\text { Sunca }\end{array}$ \\
\hline $0-8$ anos & 1 & 0 & 100 & 100 & & 0 & 0 & 100 \\
\hline $8,1-11$ anos & 11 & 81,8 & 18,2 & 72,7 & 27,3 & 63,6 & 36,4 & 0 \\
\hline $11,1-16$ anos & 16 & 81,3 & 18,8 & 100,0 & 0,0 & 75,0 & 25,0 & 0 \\
\hline $16,1-18$ anos & 1 & 100 & 0 & 100 & 0 & 100 & 0 & 0 \\
\hline
\end{tabular}

Em linhas gerais e na tentativa de traçar um perfil sócio-econômico dos participantes, a aplicação do questionário sócio-econômico nos permitiu inferir que, via de regra, os alunos têm origem urbana, passaram boa parte de seus estudos em instituições públicas, os membros de suas famílias possuem escolaridade que varia entre 8 e 16 anos em média (ensino médio e superior), têm acesso ao computador, utilizam a Internet para pesquisa e contatos pessoais e, freqüentemente, fazem a leitura de jornais e revistas.

\subsection{O questionário psicossocial}

A disciplina mais citada pelos participantes como preferida na escola foi o inglês, com 20 citações $(23,53 \%)$, de um total de 85 . Surpreendentemente, a segunda mais lembrada não está localizada nas áreas humanas, como talvez fosse de se esperar: biologia, com 16 citações $(18,82)$. As três disciplinas seguintes inserem-se nas humanas: história, com 10 citações (11,76\%): Português, com 9 (10,58\%) e Literatura, com 8 (9,41\%).

As razões para a preferência pelo inglês estão relacionadas ao fato de a língua ser atraente, à facilidade de aprendizagem e à importância de se conhecer um segundo idioma, tendo em 
vista as possibilidades que este proporciona de contato com o mundo. Vale ressaltar que os excertos analisados neste trabalho trazem, em termos de função da linguagem, declarações. Assim, ao falarem sobre a preferência pelo inglês, utilizam declarações factuais ('realis' statments) (Fairclough, 2003: 109). É interessante observar que os participantes registram sua opinião assertiva por meio da modalidade epistêmica (troca de conhecimento), sem, portanto, utilizar modalizações. Parecem estar seguros do que dizem e destacam a relação afetiva que possuem com a língua, utilizando processos mentais ("me cativa", P23; "me atraem", P8 e 16). As marcas de pessoa ("eu", P25; "me", P23, ou mesmo em elipse, P16) contribuem para reforçar seu ponto de vista e seu engajamento em relação ao que têm a dizer.

Lançam mão também de processos relacionais ("ser", P23, "ter" - P25 e P16) para justificar essa relação afetiva, atribuindo alto valor a ela por meio de superlativos ("o mais charmoso", P23; "as notas melhores", "mais facilidade", P25), advérbio de intensidade ("muito", P16) substantivos avaliativos ("facilidade", P16) e advérbios de alta freqüência ("sempre", P16). Além disso, dois alunos (P8 e P16) destacam, ainda, o valor comunicativo da língua/linguagem, assumindo (P8), enquanto valor pressuposto, que saber línguas é ter acesso a outros mundos.

P23 O inglês me cativa por sero idioma mais charmoso.

P25 Eram as matérias (inglês e português) que eu tinha as notas melhores e mais facilidade em aprender.

P8 Línguas estrangeiras me atraem pela comunicação mundo a fora.

P16 Sempre tive facilidade nestas disciplinas (Português e Inglês), pois adoro linguagem e a área da comunicação me trai muito e estas disciplinas têm a ver com isso.

Já a preferência pela biologia, segunda disciplina mais citada, parece estar relacionada à uma curiosidade científica cognitiva "informacional", de entender o organismo humano e como ele funciona. Nesse caso, e embora continuem usando (via de regra) a modalidade epistêmica assertiva, os comentários demonstram um grau menor de comprometimento dos participantes. Utilizam, portanto, justificativas impessoais, por meio da estratégia de nominalização ("facilidade", P5; "estudo" e "conhecimento", P26, "interdisciplinaridade", P3) que, segundo Fairclough (2003: 12-13), contribui para mistificar e ofuscar o agente e/ou responsável pela ação.

Os processos mentais afetivos também desaparecem e os relacionais ficam mais escassos. Apenas P15 se compromete mais pessoalmente ("achava"), embora sua escolha verbal (mental cognitivo) indique, em si, uma modalização ("achar" tem menor intensidade do que "acreditar" ou "entender", por exemplo). Poderíamos interpretar o comentário de P15 enquanto uma ação/atividade e, então, teríamos o indicativo da modalidade deôntica e o comprometimento dele com tal ação. P15 utiliza, ainda, adjetivos avaliativos ("interessante", "complexo") que qualificam a importância do estudo. Mas, de todo modo, seus discursos não apresentam elementos intensificadores, como os superlativos encontrados no discurso dos participantes que preferem o inglês. A presença de processos materiais, ou seja, verbos relacionados ao "fazer" ("funcionam" - P26) indicam a relação dos participantes com o mundo real e concreto (Cabral, 2002: 19), diferente da característica de afetividade que encontramos nos exemplo já mencionados (P23,P25,P8, P16). 


\section{P5 Facilidade na matéria}

P26 Estudo da vida, conhecimento de como funcionam os serem vivos.

P15...achava interessante descobrir o quanto é complexo o ser humano.

P3 A genética. A interdisciplinaridade com a Química.

Assim, em termos gerais, podemos inferir que a preferência dos participantes pelo inglês é resultado de uma relação de intimidade, familiaridade e atração, ou seja, há uma identificação pessoal com a língua. A leitura/interesse por textos científicos, no caso, a Biologia, parece estar mais relacionada ao valor de senso comum, assumido pelos participantes, de que devemos ter acesso à essa área enquanto conhecimento geral.

No que se refere à escolha profissional, procurei saber, através do questionário psicossocial, qual foi a primeira opção de curso nos exames do Vestibular e Peies. Dos 30 participantes, um pouco menos da metade (46,66\%, 14 participantes) afirmou que Letras/Inglês havia sido sua primeira escolha profissional. Entretanto, destes, a metade (7 participantes) confessou estar fazendo ou pretender fazer outro curso. Subjacente ao seus discursos, portanto, está o pressuposto de que a Licenciatura em Inglês é um curso complementar, ou seja, seu valor está em complementar a "profissão de fato" ("Relações Públicas, P5; "Biologia", P13; "Técnico em Informática”, P19 e Tradutor -Intérprete/Turismo, P15).

Ao justificarem a escolha por outras profissões que não a de professor de inglês, os participantes se colocam como agentes de seus dizeres, utilizando, na maioria das vezes, a $1^{\text {a }}$ pessoa. Lançam mão da modalidade epistêmica para indicar seu comprometimento em direção à profissão almejada por meio de previsões (irrealis statements, Fairclough, 2003: 109) ("Farei Relações Públicas", P5) ou asserções modalizadas ("Pretendo ficar", P19). As negações servem para justificar o porquê de ainda não estarem estudando o curso desejado ("Não estou maduro", P13 e "Não estou preparado", P18) ou a intenção de não seguir a carreira de professor ("Não pretendo ser", P5).

Avaliam positivamente a profissão escolhida por meio de: a) processos relacionais afetivos modalizados ("acho que tem mais a ver comigo", P5; "tenho possibilidade de ascensão profissional", P19); b) processos materiais que dão um valor concreto às suas escolhas ("pode atuar em várias áreas e trabalhar fora do país", P9) e c) processos mentais cognitivos que dão a sensação de uma decisão que foi refletida ("Penso em ser interprete ou profissional do turismo, P15).

Classificam as profissões em escalas diferenciadas de valor. P13 entende não estar maduro para estudar Biologia e P18, não estar preparado para a Medicina, o que significa dizer que o grau de maturidade e preparo necessários para se fazer Licenciatura em Inglês é menor, já que a estão cursando. Podemos perceber, ainda, que a relação afetiva com o inglês se mantém ("pelo gosto de saber mais", P5) e que o valor dado ao Curso de Letras está diretamente associado à aprendizagem da língua ("estudar inglês é bom", P13), complementando a profissão desejada. 
P5 Eu não pretendo ser professora. Eu queria fazer inglês pelo gosto de saber mais...Farei Relações Públicas esse ano, pq. acho que tem mais a ver comigo.

P13 Eu não estou maduro suficiente para estudar biologia e estudar inglês é muito bom.

P9...tradutora interprete, pois pode atuar em várias áreas e trabalhar fora do país.

P19 Tenho curso técnico em informática e atuo na área. Pretendo ficar no meu trabalho atual pois tenho possibilidade de ascensão profissional.

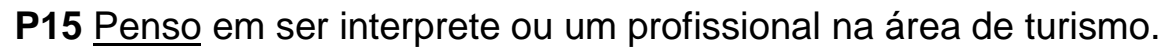

P18 Medicina, porque eu me interesso pela área. (Não estou) preparado para prestar vestibular para o curso.

Dos participantes que fizeram a escolha por Letras/Inglês como primeira opção no Vestibular/Peies (46,66\%), 7 deles $(23,33 \%$ do total de participantes que responderam aos questionários) declararam o desejo de atuarem como professores. Para dar consistência e alto valor a suas justificativas, escolhem processos mentais cognitivos, intensificados por advérbios ("sabia muito", "conhecer mais", P27) e processos mentais afetivos também associados a advérbios (de alta freqüência - "eu sempre gostei", sempre ia bem", P10; e comparativos de superioridade - "gostava mais... do que qualquer outra coisa", P28). Contudo, algumas vezes, utilizam a modalidade epistêmica mais modalizadamente (queria conhecer", P27 e "queira ser") para justificar sua opção por Letras. Ao escolher um processo relacional ("ter") e um particípio com função de adjetivo ("reconhecido"), P27 valoriza a profissão de professor, quando expressa o desejo de ter um diploma reconhecido.

P27 ...já sabia muito da língua, mas queria conhecer mais e ter um diploma reconhecido.

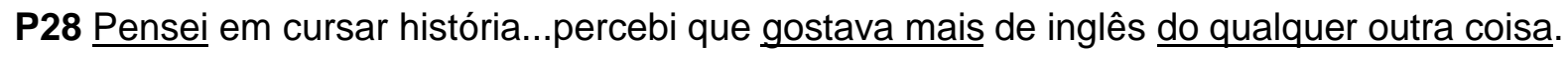

P10 Eu sempre gostei de inglês, na escola eu sempre ia muito bem, mas descobri que queria ser professor no ano passado.

É claro que podemos atribuir à imaturidade - a idade média dos entrevistados é 21,5 anos, e ao reduzido contato com o processo de ensino/aprendizagem da língua (apenas $26,66 \%$ estão trabalhando em projetos de monitoria na universidade e, também do total, somente 23,33\% já tiveram alguma experiência com o ensino de inglês) as múltiplas escolhas profissionais. Só para se ter uma idéia, entre os participantes que não colocaram Letras/lnglês como primeira opção, a gama de cursos preferidos é bastante diversificada: Biologia (3) Medicina (2), História (2), Administração (2) e uma citação para Ciências da Computação, Letras/Português, Publicidade, Espanhol, Arquitetura, Psicologia e Relações Públicas. A pergunta que fica é: Por que esses alunos estão cursando Letras/Inglês?

As explicações se aproximam muito daquelas dadas pelos participantes que, embora tenham escolhido Letras/Inglês como primeira opção, estão ou desejam fazer o curso complementarmente a outro ("estou cursando o $7^{\circ}$ semestre de História", P4; "Inglês ainda é um complemento para o curso de jornalismo", P14; e "Pretendo cursar Medicina", P23). P12 numera, em ordem de importância, sua opções, deixando Letras/Inglês em último. 
Utilizam, na maioria dos comentários, a modalidade epistêmica assertiva factual (realis statements), com alguns exemplos de previsões ou irrealis statements ("vou trabalhar", P4 e "Pretendo cursar", P23). Considerando que os processos relacionais atribuem valor ao que desejamos expressar, em P12 e P14 esse valor é negativo. O uso do verbo "ser" constrói o argumento de que o Curso de Letras/Inglês assume posição secundária em suas vidas acadêmicas, idéia acentuada pelos advérbios "enfim" e "só" e pelo substantivo avaliativo "complemento". Já em P4 e, novamente, em P12, os verbo " estar" e "ser", utilizados no presente, indicam a importância dada a outro curso, que também é salientada por substantivos avaliativos ("primeira opção", P12). Por fim, podemos perceber que P12 e P23 só estão fazendo a licenciatura, pois o ponto de corte era menor. Este, de fato, determinou sua entrada no curso e os impossibilitou de fazer o curso desejado, ora mais competitivo.

P4 Eu sempre quis aprender outra língua, e quando comecei a estudar Inglês, me interessei pelo estudo da linguagem. (...) estou cursando o $7^{\circ}$ semestre de História. Eu acho que vou trabalhar com as duas licenciaturas.

P12 O ponto de corte (no vestibular). A primeira opção é Ciências da Computação, a segunda era Agronomia e a terceira enfim era Letras/Inglês.

P14 Inglês ainda é, para mim, só um complemento para o curso de jornalismo.

P23 Não tive um bom Ensino Médio e foi muito complicado adquirir conhecimento em todas as matérias exigidas no vestibular. Pretendo cursar Medicina e já curso Química nessa [sic] instituição.

Equacionando os resultados, temos 23,33\% (7 participantes) que demonstram o desejo de serem professores de Inglês e outros $76,66 \%$ (23 participantes) que estão fazendo Letras/Inglês porque se trata de um conhecimento complementar à carreira que desejam seguir e, em alguns poucos casos, uma opção profissional simultânea. Enquanto crença naturalizada e compartilhada entre os participantes, os depoimentos revelam que o curso de Licenciatura em Inglês se trata de uma boa oportunidade para aprender uma segunda língua, enquanto o estudo da profissão "escolhida" não acontece devido à imaturidade ou despreparo para enfrentar o concorrido vestibular. Ortenzi, Mateus e Reis (2002) chegaram a conclusões semelhantes. As autoras trabalharam com alunos em estágio inicial de aprendizagem e concluíram que o curso de Letras não é primeira opção. Quando aparece em primeiro lugar, tal escolha está relacionada à aprendizagem da língua estrangeira.

\subsection{As Narrativas dos alunos}

A história contada pelos participantes (em relação ao momento da escolha e o que os motivou a fazer Letras) reforça a hipótese levantada por Ortenzi, Mateus e Reis (2002) de que o interesse pelo curso de Letras está relacionado à possibilidade de acesso à aprendizagem de línguas e às oportunidades que o conhecimento destas pode trazer, como "viajar" (N2), "estudar Turismo" (N3) ou "Tradutor/Interprete" (N4). Tais argumentos são reforçados pelo uso de substantivos avaliativos ("vantagem" e "sonho", N3), na relação estreita que o narrador estabelece entre o conhecimento da língua estrangeira e essas profissões, utilizando um 
advérbio de alta freqüência e gerúndio ("sempre lidando com línguas", N3) ou construindo a idéia de que tal conhecimento facilitaria seu objetivo-fim - viajar ("seria mais fácil", N2).

Vale ressaltar que, assim como nos comentários retirados do questionário psicossocial, identificamos, nas narrativas, o uso de declarações (modalidade epistêmica), que exploram fatos (realis statements) e a presença da primeira pessoa, que comprometem os narradores com o valor de verdade subjacente aos seus textos. A relação afetiva com a língua está novamente marcada pelo uso de processos mentais afetivos, acentuados por advérbios de intensidade ("gosto", N2; "gostava muito", gosto de aprender, N3); por processos relacionais associados a atributivos afetivos ("sou apaixonado", N2), ou, ainda, pela relação de proximidade estabelecida por meio de processo mental cognitivo associado a um advérbio avaliativo ("me sinto mais confortável", N4).

A Licenciatura em Letras não é vista enquanto profissão por si e em si ("fazer só ele e deu. Ser professora de inglês, no caso, e só", N6). O uso do advérbio "só" dá ao curso um valor de inferioridade ou incompletude e naturaliza a idéia de que o mesmo é apenas um complemento acadêmico. Enquanto opção, Letras parece estar entre os últimos lugares e ser associada à necessidade de sobrevivência, que é estabelecida pela construção condicional ("caso precise, algum dia, dar aula", N4) ou, ainda, à falta de alternativa melhor ("assim, né, eu fiz Letras, mesmo", N3). Neste caso, as escolhas verbais associadas ao substantivo avaliativo "eliminação" e ao advérbio "mesmo" de N3 ("acabei optando" e "fui fazendo eliminação", "fiz, Letras, mesmo") explicitam como a falta de opções levou à aluna ao curso de Letras.

N2 Porque eu gosto da língua, de inglês, eu sou apaixonado por falar inglês, pela cultura dos Ingleses/dos Britânicos e dos Americanos, porque eu achei que com o inglês teria uma vanta-

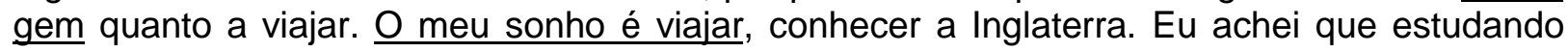
Letras, a cultura deles, seria mais fácil viajar.

N3 Fui fazendo eliminação. Eu tava meio perdida. Daí, a gente foi vendo, assim, mais ou menos o que eu gostava, eu gostava muito do Inglês, eu gosto de aprender outras línguas e, daí eu acabei optando por Letras. A gente (participante e família) pensou em Turismo também, uma coisa assim, sempre lidando com línguas, mas como aqui na Federal não tem...assim, né, eu fiz Letras, mesmo.

N4 ...se algum dia eu viesse a dar aula, seria por uma necessidade, não por um desejo, sabe. Eu tô aqui, fazendo Licenciatura, por uma necessidade. Caso precise, algum dia, dar aula. Mas o meu objetivo é ser tradutor ou intérprete. Eu acho que é uma área que eu me sinto mais confortável.

N6... não é curso que eu queria fazer só ele e deu, ser professora de inglês, no caso, e só. É uma coisa que eu quero fazer para conhecimento pessoal.

Entre aqueles que desejam ser professores (dois dos seis narradores), também identificamos algumas incertezas. N1 não parece ter dúvidas quanto ao fato de querer ser professora de inglês, mas ainda não decidiu se irá concluir a Licenciatura em Letras/Português. N5, embora demonstre desejo de ser professor, tendo percorrido um longo caminho antes de chegar ao Curso de Letras (trabalhou numa multinacional alemã, numa empresa área, como comissário de bordo e, ainda, como cabeleireiro), parece suspeitar das chances oferecidas pelo mercado para atuar como professor de inglês. 
N1 Quando eu fui fazer Vestibular, eu não sabia se fazia Inglês ou Português. Eu decidi fazer Português primeiro, por causa da Literatura, eu gostava de Literatura....eu decidi fazer vestibular de novo para Inglês. Eu estou fazendo os dois. Eu não me decidi, se continuo ou paro de fazer Português.

N5 (Decidi por Letras) logo após o $2^{\circ}$ Grau. Todos os meus colegas fizeram, a maioria, os mais chegados, assim, da turma, e eu tive que adiar isso para aceitar uma proposta de emprego em São Leopoldo...depois de um ano, eu senti que não era por aí, essa área industrial, escritório, não era para mim, eu queria mesmo, eu sempre fui bem em português e nas aulas de inglês, eu tive que adiar um pouco, mas agora consegui....pelo currículo novo, que separou o inglês do português, eu pesei bastante e decidi pelo inglês. Eu acredito que o mercado, até mesmo se der algum problema no decorrer da história, que eu não consiga seguir a Licenciatura, dar aula. Nesse caso e tal, eu posso voltar para a aviação, com inglês, se for o caso, mas não é minha intenção.

Assim, podemos dizer que quatro dos narradores (N2, N3, N4 e N6) reforçam a concepção, identificada na maioria (aproximadamente 76\%) dos comentários extraídos do questionário psicossocial, de que o Curso de Letras é visto enquanto curso de línguas, sendo o conhecimento de inglês, ou seja, a aprendizagem do idioma, o real valor atribuído à licenciatura. Nesses casos, os alunos não se reconhecem "Professores de Inglês". N5, por outro lado, quer sê-lo e, assim como ele, N1 e cerca de $23 \%$ dos participantes que responderam ao questionário psicossocial. Entretanto, o desejo de ser professor em N5 vem acompanhado de uma certa angústia e preocupação (também observadas nas narrativas de outros participantes) em relação às chances que terá de exercer a profissão.

\section{CONSIDERAÇÕES FINAIS}

Parece ser correto afirmar que o discurso dos futuros professores de inglês deixa transparecer um sentimento "de falta de", uma sensação de incompletude. Acredito que tal sentimento acompanhe qualquer profissional em processo inicial ou adiantado de formação. Como afirma Hall (2005: 106), a Identificação é um processo de articulação. "Há sempre 'demasiado' ou 'muito pouco' - uma sobredeterminação ou uma falta, mas nunca um ajuste completo, uma totalidade" (Idem: Ibidem). Entretanto, podemos igualmente observar, no discurso desses futuros profissionais, uma dificuldade ou uma impossibilidade de se perceberem, se reconhecerem ou mesmo se intitularem "Professores de Inglês".

Em conseqüência, não se constituem enquanto classe, não se vêem enquanto grupo, como é comum observarmos, por exemplo, em estudantes de medicina. Fazem questão de vestir seus jalecos já no primeiro semestre - ou assim que puderem, e desfilar pelo campus com seus estetoscópios pendurados no pescoço, ansiosos para dizer ao mundo a que grupo pertencem. Embora pareçam um tanto pretensiosos ao olhar de muitos, carregam o que podemos chamar de identificação nômica (Elias \& Scotson, 2000: 179). Esta lhes garante coesão e um sentido de unidade em relação a um grupo ao qual, acima de tudo, têm orgulho de pertencer.

O aluno de Letras, além da sensação de incompletude, tão própria da sociedade pósmoderna, parece carregar um sentimento de isolamento, de solidão identitária, que pode ser percebida no seu processo inicial de formação, como sugere esta pesquisa. Entendo que os cursos de licenciatura precisam problematizar a questão, procurando discutir, com seus alu- 
nos, qual o profissional que desejam colocar no mercado e, por conseguinte, quais prioridades devem ser estabelecidas para que esse objetivo seja alcançado. A discussão do processo de construção identitária do professor de línguas, me parece, deve integrar essas prioridades, de modo que ele, ao final de um longo dia de trabalho, também tenha orgulho de se auto-intitular "Professor de Línguas" ou "Profissional da Linguagem".

\section{BIBLIOGRAFIA}

ABRAÃO, M.H.V. (2004). Crenças, pressupostos e conhecimentos de alunos-professores de língua estrangeira e sua formação inicial. In: M.H.V ABRAÃO (Org.). Prática de ensino de língua estrangeira: experiências e reflexões. Campinas: Pontes Editores, p. 131-52.

BERGER, P. \& LUCKMANN, T. (1985). A construção social da realidade. Petrópolis: Vozes.

CABRAL, S. ( 2002) Estrutura textual e transitividade: a carta do leitor como construção da experiência. Dissertação de mestrado. UFSM.

CASTRO, S. T. R. (2004). Representações de alunos de inglês de um curso de letras. The ESPecialist, 25 (especial): 39-57

CELANI, M. A. A. \& MAGALHÃES, M. C. (2002). Representações de professores de inglês como língua estrangeira sobre suas identidades profissionais: uma proposta de reconstrução. In: L. P. MOITA LOPES \& L.C. BASTOS. Identidades: recortes multi e interdisciplinares. (Orgs.). Campinas, SP: Mercado de Letras, p.319-37.

CELANI, M. A. A. (2001). Ensino de línguas estrangeiras - ocupação ou profissão. In: V. LEFFA (Org.). O professor de línguas estrangeiras - construíndo a profissão. Pelotas: Educat, p. 21-40.

ELIAS, N. \& SCOTSON, J. L. (2000). Os estabelecidos e os outsiders. Rio de Janeiro: Jorge Zahar.

FAIRCLOUGH, N. (2003). Analysing discouse: Textual analysis for social research. London/New York: Routledge.

GIMENEZ, T. (2004). Tornando-se professores de inglês: experiências de formação inicial em um curso de Letras. In: M.H.V ABRAÃO (Org.) Prática de ensino de língua estrangeira: experiências e reflexões. Campinas: Pontes Editores, p. 171-87.

GRIGOLETO, M. (2005). Ideologia e processos identitários: o simbólico em questão. In: M. M. FREIRE, M. H. V. ABRAÃO \& A . M. F. BARCELOS. Lingüística aplicada e contemporaneidade. São Paulo: Pontes Editores.

HALL, S. (2005). Quem precisa da identidade? In: T.T. SILVA (Org.). Identidade e diferença: a perspectiva dos estudos culturais. Petrópolis: Vozes, p.103-33.

HALLIDAY, M. (1004). An introduction to functional grammar. 2 ed. London: Edward Arnold. 
ORTENZI, D; MATEUS, E. F. \& REIS, S. (2002). Alunas formandas do curso de letras angloportuguesas: Escolhas, marcos e expectativas. In: T. GIMENEZ (Org.). Trajetórias na formação de professoras de línguas. Londrina: Editora UEL, p. 143-156.

TELLES, J. (2002). "É pesquisa, é? Ah, não quero, não, bem!" Sobre pesquisa acadêmica e sua relação com a prática do professor de línguas. Linguagem \& Ensino, 5(2): 91-116.

(1999). A trajetória narrativa: Histórias sobre a formação do professor de línguas e sua prática pedagógica. Trabalhos em Lingüística Aplicada, 34 (Jul./dez.): 79-92.

PAIVA, V. M. O. (2005). Memórias de aprendizagem de professores de língua inglesa. Em: http://www.veramenezes.com/narprofessores.htm. Atualizado em 31/05/2005.

RAJAGOPALAN, K. (2002). A confecção do memorial como exercício de reconstituição do self. In: L. P. MOITA LOPES \& L.C. BASTOS. (Orgs.) Identidades: recortes multi e interdisciplinares.

Campinas, SP: Mercado de

Letras.

P.339-49. 
ANEXO A - Média Educacional, Origem Familiar e Tipo de Instituição de Ensino
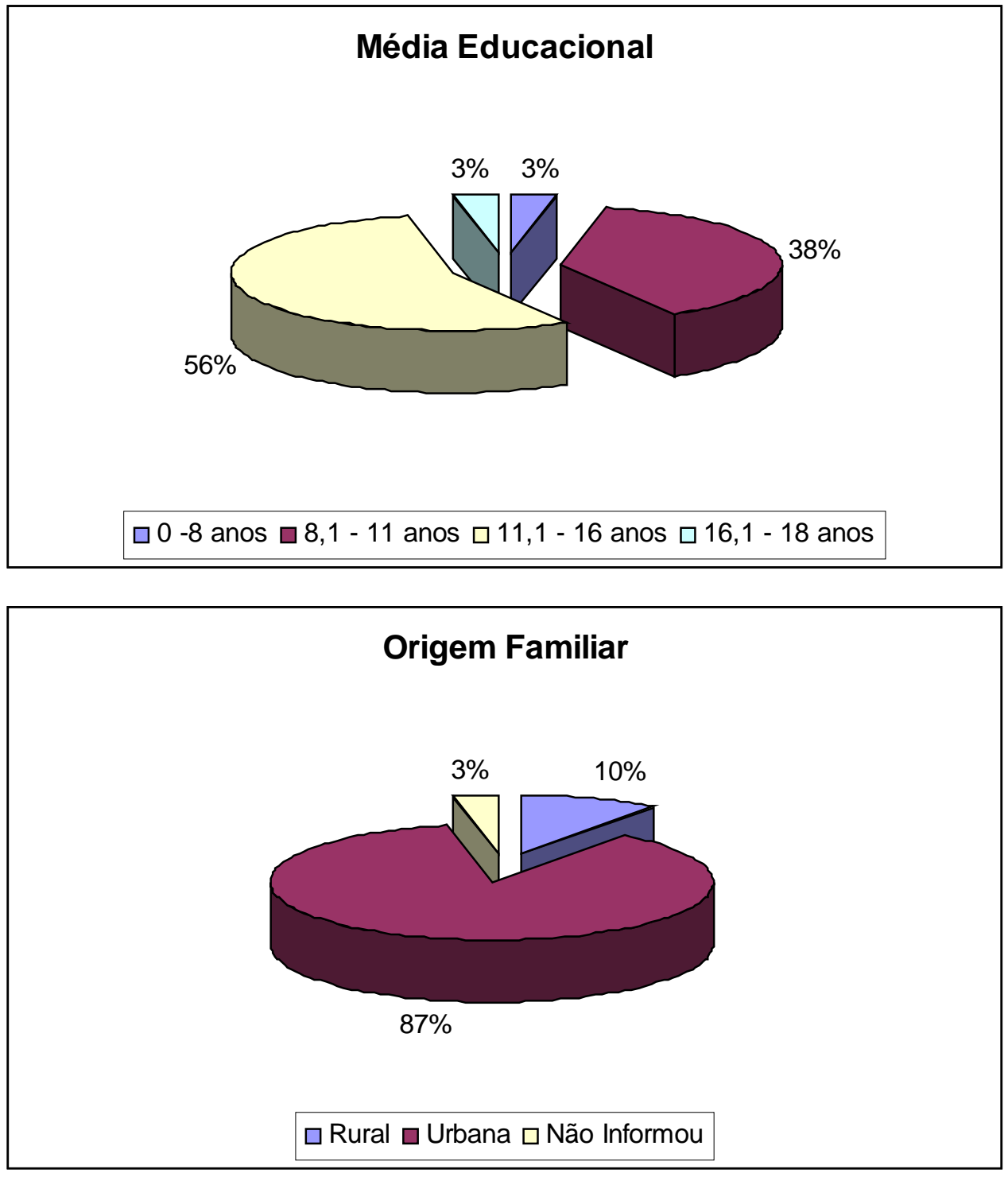

Tipo de Instituição de Ensino

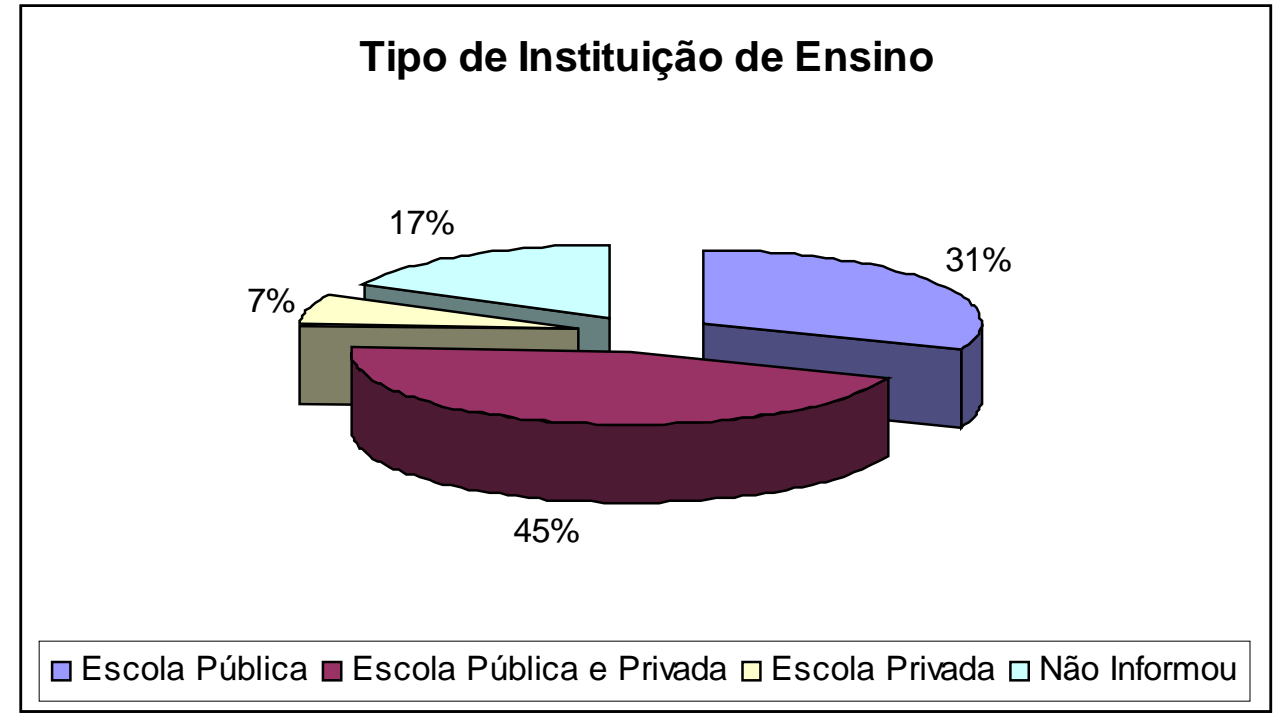

PDF created with FinePrint pdfFactory Pro trial version http://www.fineprint.com 